ISSN: 0213-2079 - ISSN electrónico: 2386-3889

DOI: https://doi.org/10.14201/shhmo2019412221247

\title{
AMBROSIO SPÍNOLA: ENTRE LA CIFRA PRIVADA Y EL ESPIONAJE DURANTE EL REINADO DE FELIPE III
}

\author{
Ambrosio Spinola: between the encrypting and espionaging \\ during the reign of Philip III
}

\author{
Asunción RETORTILLO ATIENZA \\ Universidad de Burgos \\ Correo-e: aretortillo@ubu.es
}

Fecha de recepción: 30 de junio de 2018

Fecha de aceptación: 19 de abril de 2019

RESUMEN: El presente trabajo tiene como objetivo analizar las tácticas utilizadas por Ambrosio Spínola con relación a lo que se ha denominado diplomacia secreta. A lo largo del siglo XVI se legitimaron, desde el punto de vista moral, todas las formas de proceder de un soberano destinadas a defender su propio estado. Por ello, el desarrollo del cifrado de cartas, las redes de informantes y, en general, el espionaje creció exponencialmente. Con el aumento de su utilización estos modos de información o comunicación se hicieron imprescindibles en poco tiempo para el ejercicio de la política exterior de todos los estados europeos modernos. Este mismo proceso se extendió a la formación de militares y diplomáticos que incluyeron los métodos mencionados en el desempeño de su trabajo.

Dentro de esta nueva forma de hacer política, se generalizó el uso de la cifra en las comunicaciones de lápiz y papel, haciendo de la criptografía el más valioso y efectivo sistema para evitar que los correos interceptados revelasen el contenido de las cartas. De igual forma, surgieron las redes oficiales y privadas de informantes que se integraron en el organigrama de la administración. Con todo ello este trabajo pretende profundizar en el modo de intercambio de información sensible entre Spínola y el rey, así

Ediciones Universidad de Salamanca / అ@@ Stud. his., H. ${ }^{a}$ mod., 41, n. 2 (2019), pp. 221-247 


\section{ASUNCIÓN RETORTILLO ATIENZA \\ AMBROSIO SPÍNOLA: ENTRE LA CIFRA PRIVADA Y EL ESPIONAJE \\ DURANTE EL REINADO DE FELIPE III}

como el origen y trascendencia de la red de agentes manejada por Ambrosio. Por último, se estudia el uso que el marqués Spínola hizo de estos sistemas y el alcance que lograron en el desarrollo de su actividad política y militar.

Palabras clave: Ambrosio Spínola; comunicaciones modernas; cartas cifradas; Historia Militar; diplomacia secreta.

ABSTRACT: This study aims to analyze the tactics used by Ambrosio Spínola in relation to the called secret diplomacy. All sovereign strategies intended to defend his own state were legitimated morally during the 16th century. For this reason, the development of encryted letters, informer networks and, in general, espionage grew exponentially. With the increasing use, these modes of communication or information became, in a brief time, essential for the exercise of the foreign policy of all modern European States. This process of legalization was extended to the training of soldiers and diplomats that included the methods referred to in the performance of their jobs.

The encrypted use in communications was widespread within this new way of doing politics. So, the cryptography became the most valuable and effective system to prevent intercepted mails from revealing the letters' contents. Official and private networks of informers emerged similarly, which were integrated into the administration's organigram. With all this work aims to deepen in the mode of exchange of sensitive information between Spínola and the King, as well as the origin and significance of the agent's network managed by Ambrosio. Finally, it studies the Marquis Spinola's use of these systems and their effect on the development of its political and military activity.

Keywords: Ambrosio Spínola; modern communications; encrypted letters; Military History; secret diplomacy.

\section{LA DIPLOMACIA SECRETA EN EUROPA EN EL SIGLO XVI ${ }^{1}$}

En la época moderna la progresiva importancia de la utilización de las comunicaciones ocultas por parte de los soberanos europeos estuvo íntimamente relacionada

1. Las abreviaturas utilizadas a lo largo del texto corresponden a BNE (Biblioteca Nacional de España, Madrid), AGS (Archivo General de Simancas, Simancas - Valladolid) Estado (E), AGR (Archive Général du Royaume, Bruselas) Audience (A).

Ediciones Universidad de Salamanca / అ@@ Stud. his., H. ${ }^{a}$ mod., 41, n. 2 (2019), pp. 221-247 
ASUNCIÓN RETORTILLO ATIENZA

AMBROSIO SPÍNOLA: ENTRE LA CIFRA PRIVADA Y EL ESPIONAJE

DURANTE EL REINADO DE FELIPE III

con las novedades ideológicas que surgieron en el siglo XV influidas por el Humanismo. En la época medieval había aparecido un nuevo género literario denominado espejo de príncipes constituido por un conjunto de consejos y recomendaciones de gobierno destinados a la educación de los futuros gobernantes. Este género, y la filosofía del poder en general, se vieron afectados de forma directa por las nuevas corrientes de pensamiento que circulaban en Europa. Como consecuencia de ello en los siglos XV y XVI se multiplicaron los escritos en los que se defendía la monarquía como la forma más útil de gobierno. En ellos se opinaba que los soberanos debían emular a los que habían ejercido bien el poder en el pasado y se explicaban cuáles eran las normas consideradas apropiadas para «el buen gobierno».

Erasmo de Rotterdam en su obra Institutio principis christiani - escrita en 1516 y dedicada al futuro emperador Carlos $\mathrm{V}$ - ahondó en la idea de que el príncipe era el espejo de sus vasallos, teoría estrechamente relacionada con la frase atribuida a Platón «cuál es el rey, tal es el reino»; estas palabras se convirtieron en el siglo XVII en la frase más utilizada en los ensayos de ciencia política para definir las cualidades de un monarca y las funciones de sus consejeros (Bleznick, 1955). Entre estos atributos se enumeraban las virtudes que debían tener los reyes y príncipes - firmeza, prudencia, vigilancia, prevención, etc. - así como los defectos y errores de gobierno de los que debían de huir. En este sentido, un aspecto fundamental en la formación de los futuros soberanos de la época era el estudio de las obras que señalaban que su labor radicaba en garantizar la seguridad y defensa de sus territorios mediante la vigilancia y la prevención. Estos dos conceptos son los que permitieron la legitimación de la diplomacia secreta.

Aunque las diversas teorías políticas modernas estaban de acuerdo en cuáles debían ser los objetivos de un soberano en el desempeño de sus tareas, diferían considerablemente en relación con los límites que se debían de establecer para ponerlos en práctica. Si para los erasmistas las acotaciones estaban claramente establecidas dentro de las leyes cristianas, para los seguidores de Maquiavelo y sus ideas, plasmadas en Elprincipe, estos márgenes estaban determinados por el pragmatismo necesario para ejercer el poder. Por tanto, desde el punto de vista moral, la medida para establecer una técnica legítima dependía de la evaluación del soberano. Este hecho supuso que, dependiendo del país o estado que se tratase, variaban los métodos utilizados para alcanzar los objetivos del buen gobierno.

Un concepto esencial dentro de estos designios era el conocimiento o la inteligencia. Los intercambios comerciales internacionales debidos a la apertura de nuevas rutas, la ampliación de la escala de los conflictos militares y, en general, las nuevas dimensiones de carácter mundial de las relaciones entre personas y países hacían preciso conocer de primera mano información fiable del funcionamiento interno de los otros estados antes de establecer cualquier tipo de relación. Los términos necesarios para formar este juicio se obtenían de dos maneras bien diferenciadas. La 
primera era la diplomacia oficial y la segunda la diplomacia secreta. Una era pública y visible mientras que la otra era invisible y anónima moviéndose en el filo de la legalidad. A la primera en ocasiones también se la ha definido como diplomacia suave, frente a la segunda que sería la versión dura. Sin embargo, las dos fueron igualmente necesarias en cualquier estrategia política o militar moderna caracterizada por el desarrollo del proceso de construcción de los estados modernos. Ambas se convirtieron en necesarias sin ser excluyentes entre sí. Especialmente el uso de la información obtenida por cauces extraoficiales se elevó considerablemente en el escalafón de los conocimientos precisos para el ejercicio del poder político, militar o diplomático. Por ello, la presencia de confidentes, espías e informadores cerca de los soberanos en los siglos XVI y XVII se convirtió en habitual.

Paralelamente, inspirados por esta nueva corriente de pensamiento y ayudados por la expansión de la prensa de libros, se produjo el florecimiento de los manuales. Estos libros estaban destinados a la instrucción de los responsables de la puesta en práctica de las actividades mencionadas, en especial de embajadores y militares. La novedad más importante de estas obras con respecto a las ya existentes estaba relacionada con la necesidad de formación de expertos en inteligencia. Los nuevos tratados incluían doctrina teórica sobre el tema, así como las características particulares que un determinado país o región geográfica buscaba en estos profesionales (Navarro Bonilla, 2012).

Los tratados militares tenían como objetivo el adiestramiento de los integrantes de todos los escalafones existentes en el ejército. En ellos, además de los conocimientos técnicos y de manejo de las armas, se incluían las prácticas de espionaje y el uso de agentes e informadores como un elemento más que se debía utilizar para obtener la victoria en la batalla. Dentro de estos textos se analizaba el papel de la inteligencia secreta en la dirección y gobierno. Si dentro de la política general este aspecto era importante, en la esfera militar podía suponer la diferencia entre la victoria y la derrota.

En el ámbito diplomático, al igual que ocurrió con los manuales y tratados para la formación de los soberanos, fueron numerosos los escritos y libros dedicados a exponer las cualidades del perfecto embajador. Entre estos atributos destacaba por encima del resto las dotes de ocultación y disimulo. Antonio de Vera y Zúñiga, autor de El embajador - publicado en 1620-definía el secreto como el «fundamento del edifico, el timón de la nave, el freno del caballo» (Navarro Bonilla, 2012: 283). Los embajadores se convirtieron en la cabeza invisible de las redes de información de un país en otro. Eran los encargados de su creación, organización y funcionamiento. Las relaciones encriptadas que estos enviaban a sus soberanos contenían averiguaciones que incluía desde chascarrillos o comentarios sueltos escuchados en la corte en la que desempeñaban su cargo, a informaciones concretas y fidedignas sobre asuntos trascendentales. Estos datos eran facilitados por los informadores y 


\section{ASUNCIÓN RETORTILLO ATIENZA \\ AMBROSIO SPÍNOLA: ENTRE LA CIFRA PRIVADA Y EL ESPIONAJE \\ DURANTE EL REINADO DE FELIPE III}

espías que normalmente trabajaban al servicio del embajador. En el campo de la diplomacia secreta son especialmente reveladoras, por la cantidad de información que aportan, las relaciones que los embajadores venecianos enviaban al Dogo desde las cortes europeas.

Además de las redes oficiales de informantes que recibían órdenes directamente del rey o los embajadores ${ }^{2}$, en España se crearon también grupos de agentes en puntos estratégicos de la corona española. Estas redes de inteligencia, a diferencia de las anteriores, estaban regidas por organizaciones privadas ligadas a la corona mediante contrato (Echeverría Bacigalupe, 1998: 29). Un ejemplo de este tipo de espionaje es el surgido a principios del siglo XVI en torno a la principal preocupación de la corona española en ese momento: la lucha contra los turcos en el Mediterráneo. Este espacio se convirtió en esas décadas en el ámbito propicio para la creación de entramados de informantes como los organizados por Jerónimo Bucchia (Bertomeu, 2006: 26). O el grupo de agentes establecido por el fraile franciscano Diego de Mallorca cuyo proyecto se inició después de la batalla de Lepanto contra los turcos (Varriale, 2014: 147). Ambos, tenían como objetivo recabar la mayor cantidad posible de información en relación con el movimiento de los barcos turcos por el Mediterráneo: donde recalaban los barcos y para qué, cuantos hombres reclutaban, de qué armas disponían, qué apoyo recibían en los puertos, qué tipo de comercio realizaban, etc. Toda esta información era enviada a la península, donde en muchas ocasiones se recibía sin filtrar. El incremento de la información recibida, no sólo del Mediterráneo si no de cualquier parte del mundo, obligó a tomar medidas prácticas de organización en la corte.

En este ambiente, desde principios del siglo XVI la monarquía hispánica fue pionera en la articulación de un sistema organizado de inteligencia. Desde el reinado de Carlos V se pusieron en marcha paulatinamente una serie de organismos y cargos específicos, dependientes del Consejo de Estado, destinados a dotar de carácter oficial esta práctica y a estructurar la misma. Estas medidas fraguaron en los últimos años del reinado de Felipe II con la creación del cargo de «espía mayor», cuya función era la de coordinar y filtrar las informaciones de todos tipo - políticas, económicas, sociales... - que se recibían de distintos puntos del globo. Inspirado en esta práctica Felipe III creó la Superintendencia de las Inteligencias Secretas (Carnicer y Marcos, 1998: 64) que quedó vacía de contenido práctico debido a la presencia pujante de los validos junto a los soberanos españoles del siglo XVII que absorbieron sus funciones. La importancia vital de los conocimientos obtenidos mediante el espionaje en el funcionamiento del desarrollo político interior y exterior hacía esencial el control de la inteligencia. El duque de Lerma, al igual que posteriormente el conde

2. Sobre las redes de información a nivel global en la época moderna ver BORREGUERO BELTRÁN, 2010: 23-50.

Ediciones Universidad de Salamanca / @@ Stud. his., H. ${ }^{a}$ mod., 41, n. 2 (2019), pp. 221-247 


\section{ASUNCIÓN RETORTILLO ATIENZA \\ AMBROSIO SPÍNOLA: ENTRE LA CIFRA PRIVADA Y EL ESPIONAJE \\ DURANTE EL REINADO DE FELIPE III}

de Olivares, era consciente de que, para fiscalizar a sus adversarios dentro y fuera de la corona española, debía conocer las redes clientelares que los unían, sus movimientos, pensamientos y opiniones, fortalezas y debilidades. Para ello era básico el control de los asuntos relacionados con el espionaje. La frase latina scientia potentia est - atribuida a Hobbes y Bacon entre otros - es realmente la formulación escrita de la dependencia entre soberanía e inteligencia.

\section{LA CIFRA PRIVADA ENTRE AMBROSIO SPINOLA Y FELIPE III}

En la Europa moderna y hasta la época actual los informadores formaban parte de la esfera del conocimiento y el poder. Sin embargo, es evidente que la divulgación de la información devalúa su trascendencia. Cuantas más personas conozcan una información, menor valor o fuerza tiene dentro de una estrategia de cualquier tipo. Por ello, la ocultación de datos es esencial, hasta el punto de que tan importante es su obtención como el disimulo o el encubrimiento de las averiguaciones hechas.

En este sentido, el tratado anónimo de la segunda mitad del siglo XVII, L'art de déchiffrer indica que existen tres sistemas de comunicación: el oral, el escrito y la cifra, elevando esta última de categoría al mismo nivel que las otras dos. Con las palabras el hombre puede transmitir lo que conoce; con la escritura puede expresar las palabras y su pensamiento; y con la cifra se puede ocultar todo (Taracha, 1998: 109). La necesidad de velar lo escrito es prácticamente simultánea a la escritura en sí misma. Todas las culturas desde la Edad Antigua - asirios, babilonios, persas, egipcios, etc. - poseían algún método de alterar sus escritos para sustraerlos en la medida de lo posible a ojos indiscretos. El primer sistema criptográfico del que se tiene constancia física es del siglo V a.C. utilizado durante la guerra entre Esparta y Atenas.

En Europa, a lo largo de la Edad Media los sistemas de encriptado no fueron bien considerados; no estaban legitimados como válidos desde el punto de vista moral. En cierta manera, se les relacionaba con el ocultismo o la magia negra. La mala fama de la criptografía medieval está estrechamente vinculada con la traducción del hebreo de textos bíblicos, especialmente los trabajos realizados por los cabalistas sefardíes (Tamayo de Vargas, 1612: 175). Debido a su escasa utilización, en el medioevo no se desarrollaron sistemas novedosos de encriptado ni tampoco hubo una evolución significativa de los existentes. Sin embargo, gracias a los trabajos de recopilación realizados por la Universidad de París a lo largo del siglo XVI no se han perdido estos sistemas y, hoy en día, se conocen los procedimientos de cifrado de comunicaciones utilizados por diversos personajes históricos como, por ejemplo, Carlomagno.

En la Italia del Cuatrocento resurgió esta práctica de ocultar los textos escritos mediante la sustitución de unos caracteres por otros. Rápidamente este modelo, 


\section{ASUNCIÓN RETORTILLO ATIENZA \\ AMBROSIO SPÍNOLA: ENTRE LA CIFRA PRIVADA Y EL ESPIONAJE \\ DURANTE EL REINADO DE FELIPE III}

destinado a preservar el documento de ojos ajenos al emisario y receptor, se expandió por el continente alcanzando su edad de oro en la segunda mitad del XVII. El desarrollo en los métodos de encriptado estuvo basado en la complicación creciente del cifrado. Si en la época medieval el sistema de encriptado se limitaba a alterar las palabras reemplazando unos caracteres por otros, progresivamente se fueron incorporando a este proceso tablas de sustitución con listados de caracteres dobles, nulos, números e incluso diccionarios de palabras utilizadas con frecuencia o especialmente sensibles como ciudades y personas concretas. En la corona española, el uso generalizado de la cifra se inició con los Reyes Católicos, obteniendo su máximo desarrollo en el reinado de Felipe II. Fue en las últimas décadas del siglo XVII, al igual que en el resto de Europa, cuando el uso del encriptado de los documentos fue decayendo paulatinamente. La complejidad del sistema, debido a los constantes desciframientos y descubrimientos de las claves, lo hizo demasiado enrevesado convirtiéndolo en menos útil y perdiendo el carácter casi artístico que había adquirido. Desde el siglo XIX resurgió esta modalidad de comunicación, asociada al progresivo desarrollo tecnológico ligado a métodos mecánicos de escritura, como el telégrafo, la máquina de escribir, el ordenador, etc.

Otros aspectos que influyeron en el devenir del encriptado fueron los caminos utilizados para hacer llegar al destinatario el documento en cuestión. Manuel Fernández Álvarez ha subrayado la necesidad de las vías y recursos de comunicación utilizados como medios de expansión política, económica y militar en la edad moderna (Fernández Álvarez, 1989, XIX: 689-690). En la Edad Moderna, el sistema de comunicación común en distancias medias y largas era la escritura denominada de lápiz y papel. Las cartas y escritos se enviaban mediante emisarios o correos que habitualmente realizaban una misma ruta. Los correos de la corona española, con posesiones territoriales en diversos puntos de Europa, debían atravesar Francia para utilizar la ruta más rápida de comunicación con el norte de Europa. Por ello, los correos tardaban diferente tiempo dependiendo del momento de las relaciones entre ambos estados. A principios del siglo XVII, el tiempo medio que tardaba un correo normal en llevar una carta de Bruselas a la corte española era de 15 días, puesto que desde que España y Francia firmaron la Paz de Vervins en 1598 los correos pudieron atravesar de nuevo el país vecino al menos durante varias décadas. En estos casos, la ruta seguida era el denominado camino francés, que formaba parte del camino de los peregrinos a Santiago. Este trayecto desde Bruselas pasa por París, Tours, Poitiers, Roncesvalles o San Juan de Dios y Burgos ${ }^{3}$. De aquí, la ruta de los correos se dirigía al lugar en el que estuviese la corte en ese momento, Valladolid, Madrid, El Escorial, etc.

3. Cartas de Diego Ibarra a Felipe III. AGS, E, 2289, f. 91 y f. 92 . Poitiers, 6 de junio de 1607.

Ediciones Universidad de Salamanca / అ@ఠ Stud. his., H. ${ }^{a}$ mod., 41, n. 2 (2019), pp. 221-247 
ASUNCIÓN RETORTILLO ATIENZA

AMBROSIO SPÍNOLA: ENTRE LA CIFRA PRIVADA Y EL ESPIONAJE

DURANTE EL REINADO DE FELIPE III

Durante los periodos - anteriores y posteriores - en los que las relaciones entre ambos países no eran buenas, la ruta de los correos se complicaba y alargaba de forma extraordinaria. Las alternativas a este recorrido, en sentido de ida y vuelta, pasaban por dos rutas diferentes: la primera consistía en el trayecto en barco desde el mar del Norte sorteando los barcos ingleses y holandeses en el canal de la Mancha; en la segunda opción, se debía atravesar Centroeuropa - por el complicado Camino Español-, hasta Milán, de allí viajar hasta Génova y, posteriormente, trasladarse por mar hasta Barcelona en los barcos de la flota del Mediterráneo. La demora podía aumentar más si el destinatario no se encontraba en su localización habitual; por ejemplo, el rey podía haberse desplazado a su lugar de descanso en el Escorial, o estar de viaje en Portugal y, en el otro sentido de la comunicación, sus embajadores o generales - como en el caso de Spínola - podían estar en campaña en lugares remotos, poco accesibles o desconocidos. En cualquiera de estos casos, la llegada de los correos podía retrasarse o perderse definitivamente como ocurrió durante la guerra de Bohemia en 1619, que coincidió con el viaje de Felipe III a Portugal en un momento muy complicado para la situación política de Europa. Este traslado se solapó en el tiempo con el cambio de rumbo en el campo de la política internacional del rey de España en el que se produjo un viraje hacia un concepto más intervencionista, abandonando la política denominada de Pax Hispanica puesta en marcha por el duque de Lerma. Pocos meses antes del inicio del periplo real, que duró de abril a octubre de ese año, se había producido el fallecimiento del emperador Matías. Las posibilidades de que se complicase la elección del nuevo emperador procedentes de los príncipes contrarios a la casa de Austria hacían necesaria una correspondencia urgente y muy frecuente entre los diversos soberanos partidarios de los Habsburgo. Sin embargo, el traslado a Portugal del rey y todos sus Consejos, junto a sus constantes paradas en diferentes ciudades del reino dificultaron sobre manera el flujo habitual de correos. Esto provocó que algunas de las cartas del archiduque Alberto, Ambrosio Spínola y el conde de Oñate, embajador español en Viena, se perdiesen en el camino hacia la Corte y otras llegasen demasiado tarde. Por ello, las noticias de los sucesos en Alemania llegaron con más retraso del habitual, lo que ralentizó el proceso de toma de decisiones sobre un asunto de tanta trascendencia. El retraso de las comunicaciones y los correos, en el que las cartas se perdían o se cruzaban con otras en el camino, crearon en la administración española un alto grado de confusión en los meses que duró el viaje y varios después, hasta que la situación se volvió a normalizar.

Otra cuestión que se vio seriamente afectada por la pérdida de correos y la demora de resoluciones de los ministros españoles por la falta de comunicación fue la entrada en Alemania de Ambrosio Spínola encabezando el ejército español de Flandes. Federico del Palatinado había aceptado la corona de Bohemia otorgada por la Dieta, arrebatándosela al futuro emperador Fernando. Por ello la Liga Católica, a la que se había unido España, tomó la decisión de entrar en las tierras de Federico

Ediciones Universidad de Salamanca / అ@@ Stud. his., H. ${ }^{a}$ mod., 41, n. 2 (2019), pp. 221-247 
ASUNCIÓN RETORTILLO ATIENZA

AMBROSIO SPÍNOLA: ENTRE LA CIFRA PRIVADA Y EL ESPIONAJE

DURANTE EL REINADO DE FELIPE III

para obligarle a devolver el reino de Bohemia. Para esta acción militar el Consejo de Estado de Felipe tardó en decidir si el marqués Spínola debía encabezar el ejército como maestre de campo general a las órdenes del archiduque Alberto, o bien tendría el cargo de capitán general bajo mando de Felipe III, quien de este modo se implicaba abiertamente en el conflicto. Las discusiones entre los ministros españoles retrasaron la toma de decisiones sobre este asunto y dilataron la puesta en marcha del proyecto de entrada del ejército español en el Palatinado hasta 1620; aun así, nuevos retrasos hicieron que la notificación del cargo de capitán general se le llegase a Ambrosio cuando ya había partido de Bruselas junto a los tercios y entrado en el Palatinado. Pero por encontrarse en plena campaña militar, Ambrosio Spínola no tuvo conocimiento de ello ni de sus condiciones hasta noviembre de 1620 , meses después de su aprobación ${ }^{4}$.

En un caso como este, las vicisitudes con las que se podía encontrar un correo y las posibilidades de que esa información llegase a manos no deseadas se multiplicaban exponencialmente con el incremento del recorrido. Más todavía, si para asegurar la llegada de la correspondencia se enviaba la misma carta por varias rutas simultáneamente, como se hacía en caso de noticias relevantes. La comunicación escrita era relativamente fácil de interceptar y cuanto más alto fuese el nivel político de los participantes en la correspondencia, mayores eran las posibilidades de que fueran intervenidas por enemigos internos y externos. Bastaba con conocer las rutas habituales de los correos o las personas que realizaban estas tareas para poder alcanzar los escritos. Una vez que se había accedido al documento por el método que fuese, había que interpretar los símbolos que ocultaban el mensaje. Sacar a la luz la información que contenían los documentos encriptados se convirtió en una labor de cierto prestigio en las cortes europeas de la época moderna. Este reconocimiento era debido a que para ello se necesitaban conocimientos matemáticos, físicos y lingüísticos, por lo que solo personas de especial ingenio y capacidad podían desempeñar esta actividad. Habitualmente, eran estos mismos hombres los encargados de crear las cifras y contracifras, es decir, revelar los códigos de cifrado del contrario. El arte de penetrar las cartas secretas requería de un profundo conocimiento de la lengua en que estaba escrito el mensaje. Estas personas solían trabajar en los denominados gabinetes negros de los altos dignatarios europeos. Todos estos, incluido Ambrosio Spínola, tenían entre los miembros de su personal varios secretarios de lenguas para los diferentes idiomas que manejaban en su correspondencia y un secretario de cifra para escribir y transcribir los documentos.

A lo largo del siglo XVI aumentaron los elementos que intervenían en la cifra de documentos lo que produjo que se incrementara su complejidad de forma

4. Carta de Ambrosio Spinola al duque de Uceda. AGS, E, 2309, f. 249. Welstein, 12 de noviembre de 1620.

Ediciones Universidad de Salamanca / అ@@ Stud. his., H. ${ }^{a}$ mod., 41, n. 2 (2019), pp. 221-247 
ASUNCIÓN RETORTILLO ATIENZA

AMBROSIO SPÍNOLA: ENTRE LA CIFRA PRIVADA Y EL ESPIONAJE

DURANTE EL REINADO DE FELIPE III

exponencial. El encriptado de cartas llegó a considerarse como un arte sobre el que se escribieron diversos tratados. En el siglo posterior, el XVII, la criptografía alcanzó un gran auge, aunque sin aportar novedades tecnológicas significativas con respecto a los métodos de encriptado desarrollados en el siglo precedente; el cambio producido en esta centuria está más relacionado con la generalización de su uso.

Estrechamente conectado con las cartas escritas en cifra como medio de comunicación podría hablarse de otros aspectos que también intervinieron en el devenir de los hechos históricos como: el espionaje, las redes de informantes y el sistema de correos o sus rutas. Todos ellos integraron los elementos principales en la forma de trabajar de la diplomacia secreta. De hecho, para algunos autores como Goberna (2005: 5) la importancia de los servicios de inteligencia en la Edad Moderna ha sido minusvalorada en muchas ocasiones por la historiografía tradicional. En su opinión, aunque eclipsada por otros medios de acción política más espectaculares como la diplomacia oficial o la guerra, la diplomacia secreta alcanzó durante este largo periodo una importancia considerable y, de hecho, para este autor constituye uno de los aspectos fundamentales en la creación del estado moderno. Sin embargo, por el contrario, para otras corrientes historiográficas como la encabezada por John Keegan (2010: 5), la utilización de estos recursos por parte de los Estados Modernos era algo necesario, pero nunca suficiente, y limitan su influencia al mero estado de lo complementario: «la inteligencia es la criada, no la amante, de los guerreros».

El cifrado y descifrado - o contracifra - de cartas en este periodo tuvo una especial repercusión en la política exterior española. Por ejemplo, Luis Valle de la Zerda - secretario de la cifra durante los reinados de Felipe II y Felipe III - consiguió descifrar unas cartas en 1585 en las que la reina Isabel de Inglaterra acordaba con los rebeldes de las provincias de Holanda y Zelanda la cesión de varios puertos en el continente a cambio del apoyo militar y financiero de Inglaterra en la guerra de los Ochenta Años (Valle de la Zerda, 1600: 22-24). Por otro lado, en el conflicto que Francia mantenía con España en ese mismo periodo, por el apoyo que esta daba a la Liga Católica en las guerras de religión francesas sucedió de forma contraria: el matemático francés François Viète consiguió descifrar las cartas enviadas a Felipe II por sus agentes dando todos los detalles de un proyecto para derrocar al rey francés Enrique IV. La confianza de Felipe II en la impenetrabilidad de sus códigos era de tal magnitud que presentó una denuncia ante el Papa por el uso de artes diabólicas utilizadas por los galos para conocer sus secretos (Boye, 2003: 3); sin embargo, la realidad política ponía de manifiesto lo acertado de la maniobra puesto que una condena por este delito era la forma más efectiva de frenar las acciones francesas con relación a estas actividades.

Desde el ciclo histórico medieval se dio una progresiva evolución en cuanto a las características técnicas de los métodos de cifrado. Este desarrollo habría que 
ASUNCIÓN RETORTILLO ATIENZA

AMBROSIO SPÍNOLA: ENTRE LA CIFRA PRIVADA Y EL ESPIONAJE

DURANTE EL REINADO DE FELIPE III

relacionarlo directamente con el incremento de su uso y relevancia en las comunicaciones escritas. Antes del siglo XV el uso de los métodos de encriptado en la correspondencia fue muy puntual y estaba circunscrito a unas pocas personas, puesto que además los conocimientos básicos de lectura y escritura no estaban generalizados entre la población. Los sistemas criptográficos utilizados en estos siglos eran muy sencillos; consistían en la sustitución parcial de las vocales por puntos, numerales romanos o rayas; otros procedimientos eran la alteración de las letras de una misma palabra, la utilización de las letras griegas para ocultar las suscripciones latinas o el empleo de neumas (signos creados arbitrariamente que se utilizaban entre los siglos XI y XIII para escribir música) para representar las letras del alfabeto. En conjunto, si nos fijamos en la cantidad de elementos esteganográficos - literales o numéricos - que prevalecen en cada centuria, se puede argumentar que las claves de finales del siglo XV y comienzos del siguiente se componen principalmente de signos; las claves del siglo XVI son en mayor medida letras; las del siglo XVII están compuestas de letras y números; y finalmente, las del siglo XVIII solían ser exclusivamente de números (Galende, 1994: 57).

El método predilecto empleado en la correspondencia diplomática moderna de índole confidente es el llamado «nomenclátor», compuesto por un alfabeto, y una serie de palabras o frases codificadas, representándose cada una de ellas por uno o más símbolos enigmáticos. Estas «tablas cifradoras» o «códigos», encuadrados en el sistema basado en la sustitución de caracteres, constituyen un método que ofrecía bastante seguridad, y cuyo origen se localiza en la corte italiana de Mantua a comienzos del Cinquecento. No obstante, también tenían varios inconvenientes, por ejemplo: que el corresponsal que recibía el criptograma debía conocer la clave completa para poder interpretarlo, y que su criptoanálisis se podía basar en el examen de las frecuencias (Galende, 2006: 5). Es decir, se podía descifrar apoyándose en la cantidad de veces que aparece cada letra en un texto. De hecho, Luis Valle de la Zerda, fue un experto descifrador de este sistema.

Por parte de la corona española el primer sistema organizado de ocultación de la información fue el modelo denominado cifra general que comenzó a utilizarse en la corte de Carlos V. Este consistía en una tabla utilizada por los miembros principales de su gobierno en el extranjero que era común para todos. Una vez creada la cifra, se enviaba a los usuarios seleccionados que debían utilizarla en su correspondencia. Este modo de comunicación, manejado por la corona española durante varios siglos puede ser considerado como la clave diplomática maestra que se perfeccionó durante el reinado de su hijo. Felipe II estableció dos tipos de cifra, una general, para todos los altos cargos de la administración (embajadores, miembros de los Consejos, etc.) y otra particular, exclusiva para determinados miembros del gobierno con actividades de especial relevancia. La cifra general de Felipe II se cambiaba cada cuatro

Ediciones Universidad de Salamanca / అ@@ Stud. his., H. ${ }^{a}$ mod., 41, n. 2 (2019), pp. 221-247 


\section{ASUNCIÓN RETORTILLO ATIENZA \\ AMBROSIO SPÍNOLA: ENTRE LA CIFRA PRIVADA Y EL ESPIONAJE \\ DURANTE EL REINADO DE FELIPE III}

años. Se conocen de ocho tablas de este tipo, así como una cantidad importante de cifras particulares; su uso, sin ninguna variación, continuó siendo efectivo durante los reinados de Felipe III y Felipe IV. De la misma forma, durante todo el reinado de Carlos II se mantuvieron los mismos niveles y tipos de información que con sus predecesores, a pesar de las dudas de los historiadores ${ }^{5}$. Esta forma de funcionamiento era la habitual excepto si alguna circunstancia indicaba que la clave había sido comprometida, en cuyo caso se cambiaba de inmediato. Durante el reinado de Felipe III al menos en dos ocasiones diferentes se tuvo que modificar el cifrado por vía de urgencia ante la posibilidad de que la clave hubiese sido comprometida ${ }^{6}$.

La primera cifra general de Felipe II está datada en Gante el 8 de noviembre de 1556 y es considerada como uno de los mejores sistemas de encriptado de su tiempo. Su constitución es más compleja que el cifrario comentado anteriormente. Aunque esta modalidad está basada igualmente en «tablas cifradoras», las nuevas listas o relaciones se componían de un alfabeto en el que a cada letra le correspondían dos o más caracteres criptográficos compuestos por una pareja de números. Esta duplicidad en los caracteres más frecuentes evitaba los inconvenientes del descifrado por frecuencia. A continuación, se detallaban aquellas palabras o letras que poseían un valor doble y nulo, así como algunos numerales destinados a ocultar las cantidades mencionadas en un escrito. Para finalizar, como novedad, se incluía un breve diccionario de aquellos términos más usuales con su correspondiente signo cifrado, ya fuese numérico o literal (López Gómez, 2013: 124).

En la España moderna, el uso de la escritura con claves no estaba disponible para cualquier persona. El Consejo de Estado controlaba quién podía manejar este método de comunicación para lo que se requería un permiso, sin este su uso suponía un delito grave. De hecho, en el conocido enjuiciamiento de 1619 al marqués de Siete Iglesias, una de las acusaciones que se le hizo, además del presunto envenenamiento de la reina Margarita en 1611 y otros cargos, fue el uso del cifrado de cartas y documentos sin tener permiso expreso para ello (López Gómez, 2013: 124).

Sin embargo, otras personas como Ambrosio Spínola poseían, además de la general, una cifra propia para comunicarse de forma exclusiva con el rey y el duque de Lerma. Evidentemente los individuos que recibían una cifra privada eran muy pocos; exclusivamente aquellos que tenían un cargo de especial relevancia en el

5. Sobre la maquinaria de inteligencia durante el reinado de Carlos II ver: STORRS (2006).

6. Por ejemplo, en 1605 y 1617 (Minuta de despacho a Juan Andrea Doria, príncipe de Melfi, sobre la prisión de Diego Ferrer por ser sospechoso de haber revelado la cifra general AGS, E, 1932, f. 44. Valladolid, 14 de diciembre de 1605 y Carta de Juan Vivas de Cañamás, embajador español en Génova, a Felipe III sobre las medidas tomadas por los genoveses con Claudio de Mari, quien al parecer pretendía la cifra general española para entregársela al duque de Saboya. AGS, E, 1933, f. 371. Génova, 18 de julio de 1617).

Ediciones Universidad de Salamanca / @®@@ Stud. his., H. ${ }^{a}$ mod., 41, n. 2 (2019), pp. 221-247 


\section{ASUNCIÓN RETORTILLO ATIENZA \\ AMBROSIO SPÍNOLA: ENTRE LA CIFRA PRIVADA Y EL ESPIONAJE \\ DURANTE EL REINADO DE FELIPE III}

gobierno de España. Por ello, la recepción de estas claves constituía en sí misma un símbolo de reconocimiento y prestigio personal dentro de la estructura política. Hasta el punto de que en alguna ocasión, una vez fallecido el receptor de la clave, sus herederos solicitaron a la corona la continuación de esta en reconocimiento por los servicios prestados por su antepasado. El hecho de que el monarca diese cifra a una persona en concreto adquirió el carácter de reconocimiento real, por ello, aunque cierta cantidad de personas tuviesen ese privilegio, solo un número pequeño estaban autorizadas a escribir al rey de esta forma.

El marqués Spínola recibió la primera cifra propia en 1605 estando en Valladolid. Este hecho se produjo en el ámbito de las negociaciones con el duque de Lerma destinadas a perfilar su papel futuro en el ejército de los Países Bajos. Se le concedió la clave privada en ese momento tanto como una herramienta para el correcto desempeño de su trabajo, que requería de una correspondencia privada y secreta, como un símbolo de la especial relevancia que tenía para la corona española el trabajo encomendado y el dinero invertido por Ambrosio en el ejército español en Flandes ${ }^{7}$.

El papel que el marqués desempeñó en Flandes a partir de esta fecha fue fundamental para el futuro político de esas provincias ${ }^{8}$. Tras la victoria de Spínola en octubre de 1604 sobre los sitiados de Ostende, el archiduque Alberto, soberano de los Países Bajos, y su cuñado Felipe III vieron en el marqués la persona idónea para dirigir una ofensiva definitiva que terminase con la rebelión de siete de las provincias del norte. Esta guerra, que para esas fechas duraba ya más de 40 años, era una sangría constante en hombres y dinero para la corona española. Aunque Felipe II había cedido los Países Bajos a su hija Isabel y a su marido Alberto, al no tener estos descendientes directos los territorios volverían a la corona española, lo que justificaba cualquier esfuerzo económico y de hombres realizado para terminar con el levantamiento.

Ambrosio Spínola era el hombre adecuado para el cargo de maestre de campo general del ejército español porque, además de poseer grandes cantidades de dinero con que pagar a los soldados, tenía el apoyo tanto del duque de Lerma en España como del archiduque Alberto en Bruselas. Por ello, en los primeros meses de 1605, el marqués obtuvo de la corona los cargos que le daban un control absoluto sobre los tercios de Flandes. Además del puesto de mayor responsabilidad militar después del de capitán general - que ostentaba el archiduque-, se le concedió el de superintendente general de la hacienda del ejército. Este cargo, que le daba poderes absolutos sobre la gestión y distribución del dinero, sólo había sido otorgado con anterioridad al duque de Parma en unas circunstancias muy especiales y por un

7. Carta de don Pedro Franqueza al duque de Lerma. AGS, E, 624, f. 79. Valladolid, 3 de febrero de 1605.

8. Ver Retortillo Atienza, 2017.

Ediciones Universidad de Salamanca / అ@@ Stud. his., H. ${ }^{a}$ mod., 41, n. 2 (2019), pp. 221-247 
tiempo muy reducido. Por ello, la necesidad de utilizar un método de comunicación de conocimiento exclusivo por el emisor y el receptor era crucial. No solo para evitar que cualquier información militar cayese en manos enemigas sino también porque Ambrosio Spínola y el rey trataban temas muy delicados relacionados con los propios archiduques que, de saberse, podían derivar en la pérdida de confianza complicando más la relación entre Felipe III y Alberto e Isabel.

La cifra privada utilizada en la correspondencia de Ambrosio Spínola con la corona manejaba el mismo sistema que la cifra general con sus tres partes (alfabeto, caracteres dobles y diccionario) pero con una tabla encriptadora propia y exclusiva. Los textos, indiferentemente, estaban cifrados en su totalidad o sólo de forma parcial. Podían incluir, por ejemplo, sólo alguna palabra en clave, como alguna ciudad o zona donde el ejército de Flandes iba a realizar un ataque o trasladar parte de sus tropas, hacer referencia al nombre de alguna persona concreta, o estar totalmente cifrada de principio a fin. Cuando alguna de las partes recibía el documento encriptado el secretario de cifra traducía las palabras sueltas o reescribía el documento en su totalidad y se lo pasaba a su señor.

Este encriptado personal de la correspondencia con el marqués Spínola tuvo especial relevancia en dos periodos distintos del reinado de Felipe III. El primero de ellos se produjo durante la ofensiva española en las campañas militares de 1605 y 1606, las Jornadas de Frisia, contra los rebeldes holandeses en la Guerra de los Ochenta Años. El éxito del ejército español comandado por Ambrosio y la posterior negociación de tregua entre 1607 y 1609 supusieron un periodo de extraordinaria frecuencia en la correspondencia en cifra entre el rey de España y el marqués. Especialmente relevante era el secreto con el que debía llevarse la ofensiva militar de las Jornadas de Frisia. La efectividad del ataque se basó en la sorpresa al acometer a Mauricio de Nassau en su propia casa entrando en las provincias de Frisia y Holanda desde Alemania y no por mar, que además de ser el camino más corto, era la estrategia seguida hasta el entonces.

Sin embargo, el papel de Spínola en Bruselas no se ceñía a la maquinaria militar, tenía además una elevada carga política que fue aumentando con los años. La importancia del plan para el futuro de la política exterior española y de las expectativas creadas con respecto a la presencia de Ambrosio en Flandes al lado del archiduque Alberto eran cuando menos singulares. El marqués comandaba el ejército español, manejaba la hacienda de este por encima de los propios funcionarios de Hacienda y además en 1606 el rey le había encomendado unas Instrucciones Secretas - desconocidas especialmente para Alberto e Isabel-. En ellas, Felipe III le otorgaba la responsabilidad de garantizar la vuelta a la corona española de todas las provincias en caso de muerte de algunos de los archiduques y las condiciones en que debía producirse el traspaso de poderes. Por ello, el rey instó al marqués, a mantener el 


\section{ASUNCIÓN RETORTILLO ATIENZA \\ AMBROSIO SPÍNOLA: ENTRE LA CIFRA PRIVADA Y EL ESPIONAJE \\ DURANTE EL REINADO DE FELIPE III}

secreto de sus Instrucciones con su cifrado particular y a no abandonar Flandes más que en circunstancias excepcionales y durante poco tiempo: «las otras cosas secretas que se os encargaron no confían ni admiten una hora de ausencia»?.

Dado el carácter extremadamente sensible del papel del marqués en Flandes, además de su pertenencia a los Consejos de Estado y Guerra, Spínola y el rey habían acordado un sistema de comunicación que permitiera al marqués manejarse con más soltura a la hora de enviar noticias desde Flandes. El sistema que se estableció entre ambos consistía en que, con respecto a los temas más delicados, Spínola enviaba dos cartas a Felipe III; la primera sin cifra, para que se pudiese enseñar a todo el mundo - embajadores de otros estados y ministros - y la segunda cifrada, exclusiva para el rey incluyendo la totalidad de la información. Este modo de comunicación fue fundamental a lo largo de las negociaciones de la Tregua de los Doce Años. La primera fase de ellas se desarrolló en La Haya en 1608 entre fuertes medidas de seguridad debido al carácter suspicaz de los holandeses. En este periodo, el espionaje por ambas partes fue esencial para el desarrollo de las conversaciones. En ellas, el marqués encabezaba la delegación flamenca, pero obedecía órdenes directas del rey de España que era el que marcaba la pauta de las negociaciones. Hasta el punto de que el archiduque desempeñó un papel secundario en ellas. Alberto reconocía en una carta enviada a Felipe III, que había recibido cartas de Spínola, pero, como la del marqués iba con una cifra diferente de la que él tenía, no había entendido nada y se limitaba a reenviarlas a la península ${ }^{10}$.

El segundo de estos periodos históricos de particular sensibilidad política y militar durante el reinado de Felipe III en el que el uso de las comunicaciones encriptadas tuvo especial relevancia fueron los años posteriores a 1614. En esta fecha se produjo la segunda crisis entre los candidatos a heredar el ducado de Cleves Juliers, vacante desde 1609. A partir de este periodo, el archiduque, enfermo y consciente desde hacía tiempo que el futuro de sus territorios dependía de Felipe III y que estos iban a volver a la corona española en pocos años, decidió dejar en manos de Spínola toda la política exterior de los Países Bajos. Debido al papel que el marqués ocupaba en Bruselas, y a que este seguía las órdenes de Madrid, consideró que no tenía sentido su participación en la misma por lo que se desentendió de ella por completo. Durante los primeros años de su gobierno, Alberto se había presentado en Europa como líder del ejército y soberano de Flandes, sin embargo, con el tiempo debido a las circunstancias políticas y a su mala salud, abandonó el primer papel. Por tanto, las sucesivas crisis del ducado en disputa, así como la entrada del ejército español en

9. Carta de Felipe III a Ambrosio Spinola. AGE, E, 2226, f. 215. Ventosilla, 8 de noviembre de 1606.

10. Carta del archiduque Alberto a Felipe III. AGS, E, 2290, f. 73 . Bruselas, 29 de abril de 1608.

Ediciones Universidad de Salamanca / @®@@ Stud. his., H. ${ }^{a}$ mod., 41, n. 2 (2019), pp. 221-247 
ASUNCIÓN RETORTILLO ATIENZA

AMBROSIO SPÍNOLA: ENTRE LA CIFRA PRIVADA Y EL ESPIONAJE

DURANTE EL REINADO DE FELIPE III

Flandes en el Palatinado de 1620, fueron gestionadas y solventadas por Spínola en contacto directo con Felipe III.

Para evitar los retrasos y pérdidas que complicaban los contactos, en ocasiones de especial trascendencia política y militar, el marqués evitó tanto los correos oficiales ordinarios que salían de la corte de Bruselas cada varios días, como los extraordinarios que se enviaban cuando la urgencia de la noticia lo requería. Soslayando estos medios el marqués evitaba su interceptación y la posible revelación de la cifra, además de garantizar la llegada de información adicional de tipo oral trasmitida por las personas que portaban las cartas y que era complicado transmitir por escrito debido a su extensión o complejidad. En estas ocasiones trascendentales los portadores de las cartas de Spínola fueron hombres de su total confianza como su secretario primero Virgilio Piliasco y más tarde Felice Virago - u Octavio Visconti, conde de Gramalerio, uno de los hombres de Cámara del archiduque Alberto con el que Ambrosio Spínola mantuvo una estrecha relación de confianza desde su llegada a los Países Bajos. Incluso, para que estos emisarios no fuesen reconocidos llegaron a viajar disfrazados para evitar ser localizados al atravesar Francia o se trasladaron camuflados como sirvientes dentro de un grupo numeroso de viajeros. No en vano el marqués Spínola vivió en Génova durante sus primeros treinta años de vida, por lo que el arte de la diplomacia y el disimulo no tenían secretos para él.

La técnica concreta que utilizaba Ambrosio en sus cartas era el mismo modelo de encriptado que instauró Felipe II. Consistía en un nomenclátor, compuesto en su mayor parte por parejas de números, un alfabeto de letras, otro de sílabas y cantidades $\mathrm{y}$ un diccionario de términos habituales (personas, ciudades, cargos e instituciones, etc.). Pero lo más interesante de los documentos que intercambiaba con el duque de Lerma y el rey no era la tabla en sí misma, similar en su forma a todas las que circulaban por las embajadas españolas, si no la forma de utilizar el encriptado de los documentos. El marqués fue un paso más allá convirtiendo la cifra no en un fin en sí misma, si no en un nuevo método de acción política: la desinformación, consistente en divulgar y hacer llegar a los oídos apropiados información errónea. Esta estrategia componía una parte de la actividad diplomática llevada a cabo por Ambrosio Spínola en su servicio a la corona española.

El uso del juego político de la manipulación intencionada de las comunicaciones alcanzó sus cotas máximas durante las negociaciones de la Tregua de los Doce años. Tras casi cuarenta años de conflicto entre la corona española y parte de las provincias del norte el agotamiento social, económico y militar de ambos bandos era evidente; por otra parte, las paces firmadas por España con Francia en 1598 e Inglaterra en 1604 habían transformado el marco político de las alianzas internacionales. Por ello, tras dos años seguidos de pérdidas territoriales importantes, en 1607 los rebeldes aceptaron el acuerdo de alto al fuego propuesto por Spínola a instancias de la corona española y el archiduque Alberto. Este convenio inicial estaba destinado a alcanzar 


\section{ASUNCIÓN RETORTILLO ATIENZA \\ AMBROSIO SPÍNOLA: ENTRE LA CIFRA PRIVADA Y EL ESPIONAJE \\ DURANTE EL REINADO DE FELIPE III}

un acuerdo de paz o tregua más duradero que debía negociarse posteriormente. Las nuevas conversaciones se desarrollaron en La Haya en los primeros meses de 1608. Sin embargo, los intentos de entendimiento entre ambos bandos se complicaban a cada paso por el carácter desconfiado de los habitantes de las Islas ${ }^{11}$ que en todo veían algún intento de ser engañados, sospechando de forma continua sobre las verdaderas intenciones de los españoles. De hecho, los parlamentos estuvieron muy cerca de romperse en varias ocasiones a lo largo de los casi dos años que duraron.

En este período La Haya se había convertido en un semillero de intrigas políticas y diplomáticas, con enjambres de agentes, espías, diplomáticos y charlatanes procedentes de toda Europa que traían y llevaban información por las diversas cortes. Cuando Ambrosio Spínola - junto al presidente Richardot y al secretario Mancisidor - se trasladó a suelo holandés para continuar en persona con las negociaciones fue alojado en un palacio situado a pocos metros del lugar donde tendrían lugar las sesiones de la conferencia de paz. A partir de ese momento los representantes del archiduque debieron de extremar sus medidas de seguridad, por un lado, para evitar el acecho al que estaban sometidos todos sus pasos y, por otro, para obtener información de todos los movimientos de los contrarios. Espiar y evitar ser espiados. El recelo holandés hacia las actividades del marqués eran de tal nivel que incluso algunos de los miembros de los Estados Generales eran partidarios de confinarlo en el palacio para que no pudiese relacionarse con nadie ni extender sus redes fuera de esas paredes.

Spínola sabía que cada paso que diese sería escrutado de cerca y su correspondencia vigilada. Para evitar esto y poder estar al tanto de lo que se ordenaba en Bruselas, el secretario del marqués, Felice Virago, viajó constantemente entre Bruselas y La Haya trayendo y llevando en mano todo tipo de correspondencia entre este, el archiduque y Felipe III. Pero, incluso estas cartas se enviaban cifradas y solían contener información contradictoria. Por ejemplo, en la misiva dirigida al rey desde La Haya en abril de $1608^{12}$, el marqués inicia la carta con un párrafo sin encriptar, en el que expone su postura sobre el capítulo de las paces que se está negociando en ese momento. A continuación, le sigue otro párrafo parcialmente encriptado; en la parte legible, por el inicio de la frase, parece que el marqués ha cambiado de tema y que el texto cifrado que va a continuación es referido a este nuevo asunto. Sin embargo, no es así. Vuelve a tratar de forma oculta la primera cuestión, dando ahora su verdadera opinión sobre la misma. En realidad, en el

11. Los de las Islas era el término con el que se refería la administración española a las provincias durante las negociaciones de la Tregua de los Doce Años frente al de los rebeldes utilizado hasta esa fecha y que retomaron al finalizar la tregua.

12. Carta de Ambrosio Spínola a Felipe III. AGS, E, 2290, f. 202. La Haya, 29 de abril de 1608.

Ediciones Universidad de Salamanca / @®@@ Stud. his., H. ${ }^{a}$ mod., 41, n. 2 (2019), pp. 221-247 
ASUNCIÓN RETORTILLO ATIENZA

AMBROSIO SPÍNOLA: ENTRE LA CIFRA PRIVADA Y EL ESPIONAJE

DURANTE EL REINADO DE FELIPE III

primer párrafo cifrado el marqués, para despistar, da una versión completamente diferente de la que expresa en el texto sin cifra. Para informar al receptor utiliza el método de desviar la atención sobre el verdadero sentido de lo que oculta la carta. Concretamente escribía con relación a enviar los navíos a las Indias y el derecho que se atribuían los rebeldes holandeses a hacerlo sin permiso de la corona española. Sin cifrar exponía a Felipe III que dejaba en sus manos la decisión de permitir la navegación y de esta forma no «habrá dificultad ninguna» en firmar el acuerdo de paz con los holandeses. En cifra, sin embargo, escribió «desde el principio se vio este capítulo por letrados nuestros los cuales son de opinión que no comprenda ni hable de los lugares (de navegación a las Indias) de Vuestra Majestad» indicando que la navegación a América era un tema cerrado del que no se iba a tratar en las negociaciones. Con este modo de escribir, en caso de que la carta llegase a manos holandesas, aunque no se consiguiese interpretar, se incitaba al lector a pensar que la idea oculta versaba sobre un tema diferente de la que se exponía abiertamente. En definitiva, parecería que se daba esperanza a los rebeldes en cuanto a la libre navegación a las Indias dejando ver su buena disposición hacia el entendimiento, cuando en realidad este era un tema innegociable para la corona española.

\section{AMBROSIO SPÍNOLA Y LA DIPLOMACIA SECRETA}

La cifra general de los reyes españoles para comunicarse con sus altos funcionarios y la cifra particular que se concedía a personas con cargos o responsabilidades estratégicas, son los aspectos más vistosos y estudiados de todo el conglomerado de actividades que se escondían detrás de la diplomacia no oficial. Pero, además, dentro de ella estarían englobadas todas aquellas actividades, que, relacionadas con la información, adquirían valor por su ocultación o por el limitado número de personas que tenían acceso a ellas. Los gastos secretos para pagar sobornos e informantes, las redes de información que controlaban los movimientos económicos y de mercancías a gran escala en Europa, los correos y sus rutas constituían todo un entramado paralelo al de la actividad pública de la diplomacia. En general, se utilizaba el término de diplomacia secreta como antítesis para todo aquello que no usase los métodos de la diplomacia oficial (Gürkan, 2012: 25). Ambas eran necesarias y no necesariamente excluyentes. Un embajador, la cara visible de un Estado en otro, podía desempeñar ambos papeles. Se puede decir que las relaciones entre diplomacia y espionaje estaban separadas en ocasiones por una delgada línea; los dos eran medios de acción política y en la España moderna ambos, diplomáticos e informadores, dependían del Consejo de Estado (Navarro Bonilla, 2004: 185-213).

Habitualmente ambos tipos de diplomacia estaban controlados y dirigidos por el embajador que recibía órdenes y directrices concretas en las Instrucciones que se le daban junto con su destino. Sin embargo, las circunstancias específicas

Ediciones Universidad de Salamanca / అ@@ Stud. his., H. ${ }^{a}$ mod., 41, n. 2 (2019), pp. 221-247 


\section{ASUNCIÓN RETORTILLO ATIENZA \\ AMBROSIO SPÍNOLA: ENTRE LA CIFRA PRIVADA Y EL ESPIONAJE \\ DURANTE EL REINADO DE FELIPE III}

de Ambrosio Spínola en la corte de Bruselas le permitieron desarrollar una labor diplomática propia al margen de la del embajador español. Durante los diecinueve años que permaneció al lado de Alberto, este alcanzó una preponderancia dentro del organigrama político fuera de lo común. En palabras del nuncio del Papa en Bruselas Guido Bentivoglio, por las manos del marqués pasaban todos los temas relacionadas con las cosas de España (Bentivoglio, 1631: 149). Desde su llegada a Flandes había obtenido el favor de los archiduques para los que se volvió imprescindible, pero debido a sus capacidades, también llegó a serlo para el rey de España. De hecho, aunque no ostentaba el cargo de embajador, suplantó las funciones habituales de esta figura en la corte flamenca. Hasta el punto de que los embajadores españoles que coincidieron con el marqués en Bruselas tenían un cargo exclusivamente de representación, sin funciones reales efectivas, puesto que estas eran ejercidas por Spínola.

En 1603, coincidiendo con la llegada de Ambrosio a Flandes se había nombrado al marqués de la Laguna - cuñado del duque de Lerma - nuevo embajador en la corte bruselense. La pérdida de confianza en este, por sus alianzas con el Condestable, le hicieron volver a España poco después. Su sucesor, el marqués de Guadaleste - embajador entre 1606 y 1616 - tuvo una función puramente simbólica, puesto que el marqués por sus estrechas y directas relaciones con Lerma, Felipe III y el archiduque Alberto tuvo en todo momento tanto la iniciativa con respecto a la política exterior española en Flandes, como el control de todas las actividades secretas propias del cargo. Las quejas de Guadaleste fueron constantes sobre que nadie (ni el archiduque ni Spínola) le informaba de los asuntos relacionados con la corona española o del estado de las conversaciones de paz con los rebeldes, por ejemplo: "el secretario Mancisidor me ha avisado de parte de Su Alteza que envía a España al padre comisario general de San Francisco y don Diego de Ibarra un correo y el marqués Spinola a un caballero de su casa sin decirme a qué ninguno» ${ }^{13}$. Pocos meses después volvía a quejarse con respecto a las negociaciones sobre la tregua: «acá se trata de esto con tanto recato que para poder escribir algo ba sido forzoso saberlo por vía de las Islas» ${ }^{14}$. Algo similar le ocurrió en 1614 cuando surgieron los problemas sucesorios de Juliers. En sus cartas se quejaba que ambos - el marqués y el archiduque - habían enviado correos a España sobre el tema sin comunicarle antes qué estaba ocurriendo y añadía que «si Su Majestad tiene por bien que a su embajador no se avise cuando despachan pasaré por ello, que mi fin no es otro que servir con puntualidad» ${ }^{15}$. Desde el Consejo de Estado los enemigos de Spínola

13. Carta del marqués de Guadaleste a Felipe III. AGS, E, 2289, f. 143, Bruselas, 12 de julio de 1607.

14. Carta del marqués de Guadaleste a Felipe III. AGS, E, 2289, f. 192, Bruselas, 14 de agosto de 1607.

15. Carta del marqués de Guadaleste a Felipe III. AGS, E, 2296, s/f, Bruselas, 16 de junio de 1614 .

Ediciones Universidad de Salamanca / @@ Stud. his., H. ${ }^{a}$ mod., 41, n. 2 (2019), pp. 221-247 
ASUNCIÓN RETORTILLO ATIENZA

AMBROSIO SPÍNOLA: ENTRE LA CIFRA PRIVADA Y EL ESPIONAJE

DURANTE EL REINADO DE FELIPE III

intentaron de forma continuada, pero sin éxito, que el marqués se sometiese a las órdenes del embajador Guadaleste, como siempre había ocurrido con los cargos militares de los tercios de Flandes (Thomas, 2014: 220).

La siguiente persona elegida para el cargo de embajador español en Flandes fue Alonso de la Cueva, marqués de Bedmar, que fue nombrado en julio de 1618, dos años después de la muerte del anterior, lo cual es un indicativo de las dificultades para escoger a la persona adecuada y que esta aceptase el destino. A la pérdida de influencia que sufría el duque de Lerma en la corte española se unieron las presiones del archiduque y Ambrosio para controlar la elección del sustituto. Poco después de la llegada del nuevo embajador surgieron los primeros roces con Spínola debido precisamente a esta situación tan singular del marqués. Las diferencias de opinión entre ambos sobre sus funciones respectivas los llevó a reclamar del rey de España una solución para el conflicto surgido. Debido a los apoyos que Ambrosio tenía en el Consejo de Estado y a las cartas que el archiduque escribió en favor suyo, Felipe III se decantó por mantener la situación inalterada ${ }^{16}$.

Una muestra interesante, en cuanto a los métodos diplomáticos utilizados por el marqués Spínola, se puso de manifiesto durante el «affaire» de la princesa de Condé y Enrique IV de Francia en 1609. El rey vecino había mostrado un persistente interés personal en la princesa, lo que había obligado a los príncipes de Condé a abandonar Paris y refugiarse en sus tierras. Sin embargo, las presiones de todo tipo ejercidas por el rey para hacerlos volver a la corte obligaron a la pareja a refugiarse en Bruselas, donde residía la princesa de Orange, hermana de Condé. Ambrosio sospechaba que los acontecimientos relacionados con la princesa y su marido y el interés desmedido de Enrique IV en hacerlos retornar a Francia habían sido la excusa perfecta para entablar un nuevo conflicto con España más que un interés del rey de Francia por las atenciones de la princesa (Bentivoglio, 1667: 21). Por ello, no tuvo ningún inconveniente en disimular la verdad ante el embajador francés en Bruselas para ocultar el lugar en el que, a iniciativa suya, se encontraban escondidos los príncipes y evitar así la posible entrada de tropas francesas en Flandes con la excusa de hacerlos volver a París por la fuerza.

La creación y utilización por parte de Ambrosio de las redes de informantes, así como la gestión que hizo de las averiguaciones que recibía de estos es otra parte importante de la diplomacia secreta. Una de las principales características de la personalidad del marqués era de la saber escuchar. En los ambientes financieros en los que se había educado la información era vital, y cualquier comentario podía tener trascendencia. Conocer de antemano a qué o a quién se enfrentaba uno, cuáles eran los puntos fuertes y las debilidades del enemigo en una batalla o el oponente en una mesa de negociación constituían una parte importante para el éxito. Desde

16. Oficio del Consejo de Estado de 15 de diciembre de 1618. AGS, E, 633, f. 142.

Ediciones Universidad de Salamanca / @®@@ Stud. his., H. ${ }^{a}$ mod., 41, n. 2 (2019), pp. 221-247 
ASUNCIÓN RETORTILLO ATIENZA

AMBROSIO SPÍNOLA: ENTRE LA CIFRA PRIVADA Y EL ESPIONAJE

DURANTE EL REINADO DE FELIPE III

el punto de vista militar, a lo largo de su carrera puso en práctica en numerosas ocasiones la misma forma de proceder: recabar la mayor cantidad posible de información procedente de todos los ámbitos y tomar sus decisiones en base a ellas. Así ocurrió, por ejemplo, en 1604 antes de comprometerse con el archiduque Alberto para terminar con el sitio de Ostende, o en la preparación de las Jornadas de Frisia en 1605 y 1606. Esta cualidad de escuchar a los entendidos en cualquier materia es uno de los puntos de su personalidad reflejados por todos aquellos que le conocieron y escribieron sobre él como Pompeo Guistiniano o el cardenal Guido Bentivoglio.

Al inicio de la campaña de 1605, el archiduque junto a Federico de Berg - teniente general del ejército - , habían hostigado a las fuerzas de las Provincias Unidas en la provincia de Flandes. Pero a primeros de agosto les llegaron noticias de esa zona de que los soldados enemigos se estaban retirando para dirigirse hacia el norte «todos lo rendidos y espias me dicen que el enemigo va retirándose, habiendo ya embarcado el bagaje y vivanderos, pero no se sabe si querrá emprender alguna otra cosa en Flandes o Brabante» ${ }^{17}$. Después, más avanzado el verano continuó hostigando a los rebeldes en Flandes, primero en Berger op Zoop y Grave (Carnero, 1625: 528) porque sabía que había pocos soldados en esas plazas y después en Middelburg, que era una localidad muy próxima a la Exclusa por lo que era muy interesante hacerse con ella ${ }^{18}$. El agente de Ambrosio Spínola en La Haya, Thomas Gramaye, informaba de los mismo y le aseguraba que «en el campo del enemigo de Flandes habia gran mortalidad causada de la incomodidad que sufrian de las aguas, habian propuesto en partiendo de alli de romper los diques para empacharnos las aprochas» ${ }^{19}$.

Lo cierto es que, en su doble faceta de financiero y militar, la línea divisoria entre ambos aspectos de su vida era muy difusa. El marqués había desarrollado su actividad hasta los treinta años de forma exclusiva en el mundo de los banqueros y prestamistas. Por tanto, su forma de afrontar el ejercicio de las armas estaba basado en estos conocimientos: la racionalización de los recursos, el análisis de los problemas junto a la elaboración y gestión de presupuestos fueron sus prioridades en el mundo castrense. Debido a esto no es de extrañar que utilizase estas mismas conductas para temas políticos, económicos o relacionados con los tercios. Por ejemplo, Ambrosio Spínola tenía toda una legión de informantes a su servicio desde su etapa de cabeza de la familia Spínola de San Luca en Génova. Esta red de agentes y banqueros que se extendía por Europa constituía una fuente de información necesaria para sus actividades económicas. Este entramado había sido construido durante los siglos

17. Carta del conde Federico de Berg a Ambrosio Spinola. AGR, A, (legajo) 1465-1, s/f, 2 de agosto de 1605.

18. Carta del archiduque Alberto al duque de Lerma. BNE, MSS. 687, f. 425-427, Bruselas, 30 de septiembre de 1605.

19. Carta de Thomas Gramaye a Ambrosio Spinola. AGR, A, 1465-1, s/f., 5 de agosto de 1605 .

Ediciones Universidad de Salamanca / 요 Stud. his., H. ${ }^{a}$ mod., 41, n. 2 (2019), pp. 221-247 
ASUNCIÓN RETORTILLO ATIENZA

AMBROSIO SPÍNOLA: ENTRE LA CIFRA PRIVADA Y EL ESPIONAJE

DURANTE EL REINADO DE FELIPE III

XV y XVI por los miembros de la familia Spínola para poder realizar sus transacciones económicas con garantías por toda Europa. En las ciudades con tradicional movimiento económico y mercantil como Sevilla, Madrid, Amberes, Bruselas, Viena, París o Londres había miembros de la familia Spínola establecidos. Todos estos familiares, dedicados al préstamo de dinero y a las actividades financieras relacionadas, estaban asociados mediante compañías con otros banqueros. Muchos de estos últimos eran también de origen genovés - Judici, Nigrono, Serra, Balbi, Centurión...-, y muy endogámicos entre ellos, lo que hacía que cualquier gestión o solicitud de información por parte de Ambrosio Spínola pusiese en marcha inmediatamente una amplia y compleja red de comunicación.

Pero en Flandes desde 1606 funcionaba otra red privada de información, que tenía un contrato directo con la corona española. Este grupo de agentes de origen portugués dirigido por Diego López Sueyro y posteriormente por su hijo Emanuel, residentes en Amberes, estaba extendido por las Provincias Unidas y enviaban información frecuente sobre la situación económica, política y militar. La coexistencia de ambos sistemas de informantes siempre fue complicada. Además de los posibles cruces de datos que podían aportar varios sistemas de información subyacía otra dificultad. Entre el personal de la administración española en Bruselas existían dos corrientes políticas opuestas, trasposición de las existentes entre los ministros de Felipe III en Madrid. En la península las camarillas estaban encabezadas por el duque de Lerma, partidario de una resolución pacífica de los conflictos en Europa, y por el condestable de Castilla, Juan Fernández de Velasco, más inclinado a una intervención activa en los mismos. Junto al condestable estaban entre otros Diego de Ibarra, Agustín Mejía, y el marqués de La Laguna. Todos ellos habían pasado por los Países Bajos desempeñando diversos cargos y conocían de primera mano la posición y el trabajo que Ambrosio Spínola llevaba a cabo al lado de Alberto. Por otra parte, este mismo partido tenía en Bruselas un importante representante: Luis Velasco, general de la caballería en Flandes, directamente emparentado con el condestable y con el que el marqués tuvo desavenencias casi constantes. En Flandes junto a Alberto y Spínola se alineaban Íñigo de Brizuela, confesor del archiduque, y Rodrigo Lasso, su mayordomo mayor.

Los Sueyro tuvieron una relación muy estrecha con todos los embajadores españoles en Bruselas, posicionándose claramente en el bando contrario a Lerma y el archiduque. De hecho, Diego López Sueyro fue encarcelado por orden de Alberto en 1611 acusado de enviar información falsa a Felipe III con respecto a las intenciones de este de invadir la Exclusa y romper la tregua con los holandeses (Lonchay, Cuvelier y Lefevre 1935: 360, 362, 367). Sin embargo, la complicación de las relaciones con los Sueyro se produjo con la presencia creciente de Emanuel al frente de esta red, puesto que sus escritos pasaron de facilitar exclusivamente información obtenida a emitir opiniones y sugerir líneas de actuación al Consejo de Estado opuestas a las planteadas por el marqués.

Ediciones Universidad de Salamanca / అ@@ Stud. his., H. ${ }^{a}$ mod., 41, n. 2 (2019), pp. 221-247 


\section{ASUNCIÓN RETORTILLO ATIENZA \\ AMBROSIO SPÍNOLA: ENTRE LA CIFRA PRIVADA Y EL ESPIONAJE \\ DURANTE EL REINADO DE FELIPE III}

Durante un cierto tiempo la ausencia de embajador español en Bruselas hizo que los Sueyro enviasen sus relaciones directamente al Consejo de Estado, y desde este se trasmitía la información relevante a Ambrosio y el archiduque de vuelta a Bruselas. Sin embargo, a partir de la llegada del nuevo embajador en 1618 se pidió a Emanuel que informase a este de sus actividades y se entendiese con él como había ocurrido con anterioridad en Flandes y como sucedía con el resto de los embajadores de la corona. Por otro lado, los intentos de los Sueyro de intervenir en cuestiones de ámbito exclusivo del marqués como eran las políticas y militares crearon una rivalidad incómoda con Spínola; esto sucedió, por ejemplo, en relación con la participación del ejército de Flandes en el Palatinado en 1620. En esta ocasión Diego envió varias comunicaciones al Consejo de Estado señalando que el ejército de Flandes debía situarse entre Wessel y Rimberg para que los holandeses no se atreviesen a intervenir en el Palatinado ${ }^{20}$. Estas injerencias en materia de estrategia política no tuvieron buena acogida, ni por parte del marqués ni en el Consejo de Estado que en abril de 1621 encomendó al marqués que hablase con Diego López para explicarle la situación.

Según el contrato firmado en 1621 entre la corona española y los Sueyro, estos percibirían por su trabajo de información aproximadamente 14.500 escudos al año (Lonchay, Cuvelier y Lefevre, 1935: 5) de forma interpuesta a través de los miembros de la Compañía de Jesús, para evitar filtraciones. Sin embargo, el importe de lo que Ambrosio Spínola destinaba a gastos secretos dentro de las cuentas que presentaba al Consejo de Hacienda como superintendente general del ejército estaba muy por debajo de ese importe, ya que rondaba los 5.000 escudos anuales, casi tres veces menos.

Este tejido de informantes fue utilizado también en el siglo XVII para recabar información esencial en el desarrollo de un conflicto bélico en el que Ambrosio además de su fortuna personal se jugaba su prestigio militar; por tanto, utilizó estos contactos como un método más para obtener la victoria sobre los rebeldes holandeses o los príncipes protestantes. Cualquier ejército que moviese un número significativo de soldados, como el de las Provincias Unidas que reunía más de 10.000 hombres cada año para salir en campaña necesitaba víveres y dinero. Ambos se obtenían negociando en las plazas de comercio europeas. Y en todas ellas Spínola tenía un agente directo, un familiar, o un conocido que podía facilitar el rastro que dejaba este tipo de gestiones militares.

El marqués tenía además el cargo de superintendente de la Hacienda española en Flandes. En el ejercicio de este introdujo una serie de normas básicas de gestión con las que organizó la Hacienda, racionalizó el gasto y elaboró presupuestos anuales y

20. Cartas de Diego López Sueyro al Consejo de Estado de fechas 8 y 16 de junio de 1620. AGS, E, 634, f. 509.

Ediciones Universidad de Salamanca / @®@@ Stud. his., H. ${ }^{a}$ mod., 41, n. 2 (2019), pp. 221-247 


\section{ASUNCIÓN RETORTILLO ATIENZA \\ AMBROSIO SPÍNOLA: ENTRE LA CIFRA PRIVADA Y EL ESPIONAJE \\ DURANTE EL REINADO DE FELIPE III}

mensuales. Entre sus competencias estaban confeccionar cada año los presupuestos militares y controlar la distribución que se realizaba de los fondos. Ambrosio Spínola reservaba en todas las cuentas y tanteos que realizaba una cantidad específica para gastos secretos. Pagar estas actividades extraordinarias eran una cuestión fundamental a la hora de establecer los gastos del ejército. La partida destinada para gastos secretos oscilaba entre el $2 \%$ y el $5 \%$ del total de lo presupuestado. Este concepto, que aparecía literalmente de esta forma en los estados de cuentas que enviaba a Madrid, encubría los nombres de sus informantes y las cantidades concretas que percibían; ambos conceptos constituían una información muy valiosa para sus enemigos políticos en el Consejo de Estado. De hecho, cuando en torno a 1617 el poder de Lerma - apoyo de Spínola en la corte hasta esa fecha - disminuyó, el sector cortesano opositor aprovechó para solicitar la formación de una Junta de Hacienda en Bruselas destinada a examinar, entre otros asuntos, esos gastos que por su naturaleza eran absolutamente opacos para la hacienda española ${ }^{21}$.

\section{CONCLUSIONES}

La cifra general de los reyes españoles para comunicarse con sus altos funcionarios, así como la cifra particular que se concedía a personas con cargos o responsabilidades estratégicas son los aspectos más vistosos y estudiados de todo el conglomerado de actividades que se escondían detrás de la denominada diplomacia secreta. Sin embargo, los gastos secretos para pagar sobornos y espías, las redes de información públicas y privadas que controlaban los movimientos económicos y de mercancías a gran escala en Europa y por el Mediterráneo, los correos y sus rutas constituían un entramado esencial en el funcionamiento de los estados modernos. Todas las actuaciones mencionadas eran actividades, que, relacionadas con la información, adquirían valor por su secreto o el limitado número de personas que tenían acceso a ella. En general, se utiliza el término de diplomacia secreta como antítesis de todo aquello que no utiliza los métodos de la diplomacia oficial (Gürkan, 2012: 37). Un embajador, la cara visible de un estado en otro, debía organizar y coordinar las actividades derivadas de ambas facetas de su labor. Se puede decir que las relaciones entre diplomacia y espionaje están separadas en ocasiones por una delgada línea; los dos son medios de acción política y en la España moderna diplomáticos e informadores rendían cuentas al del Consejo de Estado (Navarro Bonilla, 2004). Este consejo, del que dependía todo el sistema diplomático de la monarquía hispánica, también era responsable del despliegue de agentes, el mantenimiento de un servicio de comunicación eficaz, desarrollo de técnicas criptográficas y todo el aparato de la inteligencia del estado.

21. Oficio del Consejo de Estado del 9 de abril de 1617. AGS, E, 2031, f. 27.

Ediciones Universidad de Salamanca / అ@@ Stud. his., H. ${ }^{a}$ mod., 41, n. 2 (2019), pp. 221-247 
ASUNCIÓN RETORTILLO ATIENZA

AMBROSIO SPÍNOLA: ENTRE LA CIFRA PRIVADA Y EL ESPIONAJE

DURANTE EL REINADO DE FELIPE III

Con relación a la figura del marqués Spínola sorprende el alcance de las actividades realizadas en esta materia durante su estancia en la corte de Bruselas. Si lo habitual es que la diplomacia estuviese encomendada a un embajador, el papel especial de Ambrosio - otorgado por Felipe III en consonancia con los deseos de los archiduques - le permitió suplantar las actividades del enviado español. En este sentido, el uso y gestión que Spínola hizo de esta amalgama de actividades puede considerarse como muy eficaz tanto en lo político como en lo militar. En este sentido, su forma de proceder consistía en preparar a fondo cada una de sus campañas militares: recabar la mayor cantidad de información geográfica posible del territorio en el que se debía desarrollar una acción bélica incluso viajando de incognito al área; escuchar las opiniones de sus maestros de campo, ingenieros e informantes y, después, tomar una decisión. De forma conjunta, todas ellas constituyeron otra de las armas utilizadas por el marqués en su desempeño al servicio de la corona española. El análisis del modo en que Ambrosio hizo uso de estas herramientas nos permite concluir que estas compusieron una parte esencial de sus actividades en Bruselas. Influyeron de forma determinante en su carrera personal por sus éxitos diplomáticos - como la firma de la Tregua de los Doce Años o los acuerdos de Xanten - y sus acciones con el ejército español - como las Jornadas de Frisia en 1605 y 1606 o la entrada en el Palatinado en 1620-. En consecuencia, estas acciones también afectaron de forma trascendental al desarrollo de la política exterior española de Felipe III.

Indiscutiblemente, tanto el acceso que tuvo y como el empleo que hizo Spínola de todas las actividades propias de la diplomacia secreta (manejo de la cifra privada en el encriptado de comunicaciones, la creación y control de redes de informantes, el manejo de los gastos secretos, etc.) conforman la línea de actuación necesaria seguida por los principales dirigentes del continente en la época moderna. La posibilidad de valerse de estos determinó la trascendencia de sus acciones al servicio de la corona española ganando con ello una enorme relevancia y prestigio con el que alcanzó el respeto de los gobernantes europeos del momento.

\section{BIBLIOGRAFÍA}

BERTOMEU MASIÁ, M. J. (2006). Cartas de un espía de Carlos V: la correspondencia de Jerónimo Bucchia con Antonio Perrenot de Granvela. Valencia, España: Universitat de València.

BLEZNICK, D. W. (1955). La Política de Dios de Quevedo y el pensamiento político en el Siglo de Oro. Nueva Revista de Filología Hispánica, 9(4), 385-394.

BENTIVOGLIO, G. (1631). Relación del movimiento de armas que hubo en Flandes el año 1614. Publicadas por Ericio Puteano. Libro II, Nápoles, Italia.

Ediciones Universidad de Salamanca / @@ Stud. his., H. ${ }^{a}$ mod., 41, n. 2 (2019), pp. 221-247 


\section{ASUNCIÓN RETORTILLO ATIENZA \\ AMBROSIO SPÍNOLA: ENTRE LA CIFRA PRIVADA Y EL ESPIONAJE \\ DURANTE EL REINADO DE FELIPE III}

BENTIVOGLIO, G. (1667). Relatione della fuga di Francia da Enrico di Borbone, prencipe di Condé primo prencipe del sangue reale di Francia e di quello che ne segui al suo ritorno a Pariggi. Venecia, Italia.

BORREGUERO BELTRÁN, C. (2010). Philip of Spain: The Spider's Web of News and Information. The Dissemination of News and the Emergence of Contemporaneity in Early Modern Europe. Surrey, Reino Unido: Farmham, 23-50.

BOYÉ, A. F. (2003). Viète, inventeur de l'algèbre ? Pays de la Loire, Francia: IREM,

CARNERO, A. (1625). Historia de las guerras civiles que ha habido en los estados de Flandes desde el año 1559 hasta el de 1609 y las causas de la rebelión de dichos estados. Bruselas.

CARNICER GARCÍA, C. J., MARCOS RIVAS, J. (1998). Sebastián de Arbizu, espia de Felipe II: la diplomacia secreta española y la intervención en Francia. Madrid, España: Editorial Nerea.

ECHEVARRÍA BACIGALUPE, M. Á. (1998). Flandes y la monarquía hispánica, 15001713. Madrid, España: Editorial Silex.

FERNÁNDEZ ÁLVAREZ, M. (1989). El siglo XVI: economía, sociedad, instituciones. En José María Jover Zamora (dir.) Historia de España de Menéndez Pidal, (19). Madrid, España: Espasa-Calpe.

GALENDE DÍAZ, J. C. (1994). La escritura cifrada durante el reinado de los Reyes Católicos y Carlos V. Cuadernos de Estudios Medievales y Ciencias y Técnicas Historiográficas, $18-19,159-178$.

GALENDE DÍAZ, J. C. (2006). Diplomacia cifrada hispánica durante el siglo XVI. Revista Digital Universitaria. 9(9), 1-9. http://www.revista.unam.mx/vol.7/num7/ art53/jul_art53.pdf.

GOBERNA FALQUE, J. R. (enero 2005). Los servicios de inteligencia en la historiografía española. Arbor, CLXXX (709), 25-79.

GÜRKAN, E. S. (2012). Espionage in the 16th century Mediterranean: secret diplomacy, Mediterranean go-betweens and the Ottoman Habsburg rivalry. Washington DC, Estados Unidos: Georgetown University.

KEEGAN, J. (2010). Intelligence in war. Nueva York, Estados Unidos: Penguin Random House.

LÓPEZ GÓMEZ, É. (2013). Las claves secretas de Rodrigo Calderón. Funciones y prácticas de la escritura: I Congreso de Investigadores Noveles en Ciencias Documentales. Madrid, España: Universidad Complutense de Madrid, 123-128.

NAVARRO BONILLA, D. (2004). Informes, relaciones y avisos: la producción documental del espionaje hispano en tiempos de guerra (Siglos XVI y XVII). Revista de Historia Militar, 95, 185-213.

NAVARRO BONILLA, D. (2007). Cartas entre espias e inteligencias secretas en el siglo de los validos: Juan de Torres-Gaspar Bonifaz, 1632-1638. Madrid, España: Ministerio de Defensa.

NAVARRO BONILLA, D. (April 2012). 'Secret Intelligences' in European Military, Political and Diplomatic Theory: An Essential Factor in the Defense of the Modern

Ediciones Universidad de Salamanca / అ@@ Stud. his., H. ${ }^{a}$ mod., 41, n. 2 (2019), pp. 221-247 
ASUNCIÓN RETORTILLO ATIENZA

AMBROSIO SPÍNOLA: ENTRE LA CIFRA PRIVADA Y EL ESPIONAJE

DURANTE EL REINADO DE FELIPE III

State (Sixteenth and Seventeenth Centuries). Intelligence and National Security, 27(2), 283-301.

RETORTILlO ATIENZA, A. (2017). Ambrosio Spinola, de Génova Ostende, 1569-1604. Madrid, España: Ministerio de Defensa.

STORRS, C. (2006). Intelligence and the formulation of policy and strategy in Early Modern Europe: The Spanish Monarchy in the Reign of Charles II (1665-1700). Intelligence and National Security, 21(4), 493-519.

TAMAYO DE VARGAS, T. (1621). Cifra y contracifra antigua y moderna. (BNE, MSS 8940).

TARACHA, C. (1998). ¿Cómo descubrir el secreto de una cifra diplomática? Investigaciones históricas: Época moderna y contemporánea, 18, 109-122.

THOMAS, W. (2014). The 'Spanish Faction' at the court of the Archdukes Albert and Isabella. En Vermeir, R., Raeymaekers, D. y Hortal Muñoz, J. E. Avisos de Flandes. A constellation of courts: the courts and households of Habsburg Europe, 1555-1665, $15,167-221$

VALLE DE LA ZERDA, L. (1600). Memorial de los servicios prestados a los Reyes Felipe II y Felipe III correspondencia y documentos del mismo. (BNE, MSS 994).

VARRIALE, G. (2014). El espionaje hispánico después de Lepanto: el proyecto de fray Diego de Mallorca. Studia Historica. Historia Moderna, 36, 147-174.

Ediciones Universidad de Salamanca / 요 Stud. his., H. ${ }^{a}$ mod., 41, n. 2 (2019), pp. 221-247 